\title{
Role Of C-Reactive Protein in Diagnosis of Acute Appendicitis
}

\author{
Mirza Tassawar Hussain ${ }^{1}$, Muhammad Kashif Khan ${ }^{2}$, Syed Shamsuddin ${ }^{3}$, Aabid Ali ${ }^{4}$, Erum Khan ${ }^{5}$, Ismat \\ Batool $^{6}$ \\ ${ }^{1}$ Assistant Professor, Department of General Surgery, Federal Government Polyclinic Hospital \\ ${ }^{2}$ Associate Surgeon, Department of Oncology, Federal Government Polyclinic Hospital \\ ${ }^{3}$ Associate Surgeon, Department of General Surgery, Federal Government Polyclinic Hospital \\ ${ }^{4}$ Medical Officer, Department of General Surgery, Federal Government Polyclinic Hospital \\ ${ }^{5}$ Senor Registrar, Department of General Surgery, Federal Government Polyclinic Hospital \\ ${ }^{6}$ Surgical Resident, Department of General Surgery, Federal Government Polyclinic Hospital
}

\begin{abstract}
Background: Appendicitis is a common surgical emergency and diagnostic dilemma. Making the correct diagnosis is often difficult as the clinical presentation varies according to the age of the patient and the position of appendix. The objective of this study was to identify clinical applicability of C- reactive protein, as a diagnostic test for appendicitis.

Methods: This prospective study was carried out in Federal government Polyclinic hospital, Islamabad from January to July 2019, 114 patients underwent appendectomy for clinically diagnosed acute appendicitis. The decision to operate the patient was given by senior registrar. The blood samples for C-reactive protein were drawn before taking the patient to the operating theatre. Removed appendices were sent for histopathological confirmation of diagnosis. The C-reactive protein was then compared with the results of histopathology to determine its validity. The data was entered and analysed in SPSS 23.

Results: The sensitivity, specificity, positive and negative predictive values of C-reactive protein in patients with clinical diagnosis of acute appendicitis were found to be $94 \%, 78 \%, 93 \%$ and $74 \%$ respectively.

Conclusion: CRP is helpful in making diagnosis of acute appendicitis. It is highly sensitive but has a relatively low specificity.

Keywords: Appendectomy, Appendicitis, C-Reactive protein, Emergency

Authors' Contribution:

${ }^{1,2}$ Conception; Literature research;

manuscript design and drafting; ${ }^{3,4}$ Critical analysis and manuscript review; ${ }^{5,6}$ Data analysis; Manuscript Editing.

$\begin{array}{ll}\text { Correspondence: } & \text { Article info: } \\ \text { Aabid Ali } & \text { Received: January 10, } 2021 \\ \text { Email: aabidalidr@gmail.com } & \text { Accepted: December 26, } 2021\end{array}$

Email: aabidalidr@gmail.com
\end{abstract}

Cite this article. Hussain MT, Khan MK, Shamsuddin S, Ali A, Batool I. Role Of C-Reactive Protein in Diagnosis of Acute Appendicitis. J Islamabad Med Dental Coll. 2021; 10(4):
Funding Source: Nil Conflict of Interest: $\mathrm{Ni}$

\section{Introduction}

On an emergency floor, acute appendicitis is one of the commonest operative emergencies encountered. Diagnosis is made usually on clinical grounds, with sometimes taking aid from radiological and laboratory testing. ${ }^{1,2}$ Making the correct diagnosis all the time is often difficult with only clinical tools, as its clinical presentation varies depending upon the gender and age of patients, location of appendix and the amount of inflammation. Moreover, many other diseases also mimic acute appendicitis making the diagnosis even more difficult, particularly in young females and children. Different scoring systems designed to diagnose acute appendicitis incorporate different combinations of signs, symptoms and tests, but due to overlapping of these factors in other differentials, pinpoint accuracy cannot be achieved. Dilemma remains, as appendectomy is usually carried out in patients using these same clinical scores, by clinical diagnostic expertise on individual level, that varies 
considerably, which may result in negative appendectomy of 15 to $30 \% .^{3,4}$

The developments in radiological system like ultrasound and CT scan have aided the surgeons to use them in diagnosis, but they are not widely available. If machines are available, the quality of training to interpret the images on individual level is not same, so the rate of negative explorations still remains high. ${ }^{4}$ On the other hand as a surgeon, one is always fearful of the consequences of a missed diagnosis of appendicitis that may lead to perforation, sepsis, portal pyaemia and even death in some late cases specially in old individuals. ${ }^{3,5}$ To prevent this horrible sequel of high morbidity and mortality, surgeon has to rely on his clinical skills and the option of appendectomy is usually adopted over conservation as benefit far outweighs the risk in suspected cases. The proportion of these negative explorations for acute appendicitis needs to be reduced because negative explorations are associated with significant but preventable morbidity ${ }^{4}$. Therefore, some easy, quick, interpretable tests must be used with clinical skills dominated approach of diagnosing appendicitis, to improve the diagnostic accuracy and reduce the number of negative explorations. ${ }^{5}$

In response to inflammation and infection, hepatocytes are signalled to produce C-reactive protein (CRP). Its concentration increases within hours of the stimulus and peaks in 24-48 hours and stays high as long as there is ongoing tissue injury. ${ }^{6}$ In many of the studies in which the diagnostic value of CRP was investigated, the results varied but nevertheless most of the studies supported its clinical applicability. ${ }^{7}$ CRP was found to be more accurate in diagnosing acute appendicitis, than elevated leukocyte count and neutrophil count. ${ }^{8}$

The objective of this study was to evaluate the clinical applicability of qualitative CRP analysis in patients with clinical diagnosis of acute appendicitis and its significance in reducing the number of negative explorations among them.

\section{Methodology}

This prospective study was conducted over a period of 6 months from January to July 2019 at department of General Surgery, Federal Govt Polyclinic (PGMI), Islamabad after taking ethical approval of the study. Sample size of 114 patients was calculated using WHO sample size calculator. A non-probability consecutive sampling technique was used to include patients after taking informed consent. All the patients above 12 years of age, going through appendectomy for acute appendicitis, were included in the study regardless of their gender. Pregnant patients, those with history of autoimmune diseases and the patients undergoing interval appendectomy were excluded from the study.

All the patients were given pre-operative antibiotics. After taking an informed written consent, blood samples for qualitative C-reactive protein analysis were collected before taking the patient to the operation theatre. The decision to operate the patient was made by a senior registrar on the basis of clinical findings, independent of Creactive protein level, whose results were available after the surgery. The laboratory staff were not aware of clinical findings, decisions or outcome. Qualitative serum C-reactive protein was measured by the Array protein chemistry system, USA. C-reactive protein level equal to or more than $10 \mathrm{mg} / \mathrm{L}$ was considered as high, thus dividing the patients into two groups i.e. Creactive protein Positive and $\mathrm{C}$-reactive protein Negative.

Removed appendix was sent to laboratory in formalin preparation where histopathological examination was done by the Consultant histopathologist. Histopathology was used as gold standard, to remove observation bias of different operating surgeons. Specimen of appendix, particularly its tip was examined to exclude carcinoid tumour and granuloma. The patients were divided into two groups on the basis of histopathology i.e Inflammation Positive and Inflammation Negative. 
The data was entered and analysed in SPSS 23. Sensitivity, specificity, positive and negative predictive values were calculated. CRP analysis was carried out free of cost at the hospital laboratory and all the patients in this study underwent standard treatment.

\section{Results}

Out of 114 patients, who underwent appendectomy for suspected acute appendicitis, 76 were males and 38 were females, with male to female ratio of 2:1. Table 1 shows general characteristics of patients in our study. Total $75 \%$ patients had inflamed appendix while in $25 \%$ of the patients, appendix was not inflamed. Among patients having inflamed appendix, 61(71\%) were males while 25 (29\%) were females. The negative appendicectomy was present in 15 (53\%) males and 13 (46\%) females.

Patients who had inflamed appendix, majority (94\%) had their CRP test positive. On the other hand, patients in whom the appendix was not inflamed, large number (79\%) were CRP negative. The sensitivity, specificity, positive and negative predictive values of serum C-reactive protein in patients with clinical diagnosis of acute appendicitis were found to be $94 \%, 78 \%, 93 \%$ and $74 \%$ respectively. (Table 2 )

Out of the 28 patients whose appendices did not show inflammation, majority had non-specific abdominal pain $(61 \%)$ followed by ruptured ovarian cyst (14\%) (Table 3).

\begin{tabular}{|l|l|}
\hline $\begin{array}{l}\text { Table 1: Baseline characteristics of patients } \\
\text { (n=114) }\end{array}$ \\
\hline Characteristics & Value \\
\hline Age-years. & \\
Mean \pm SD & $24.91 \pm 9.45$ \\
Range & $(12-55)$ \\
\hline Gender & \\
Male-n (\%) & $76(67)$ \\
Females-n (\%) & $38(33)$ \\
\hline CRP & \\
Positive-n (\%) & $87(76)$ \\
Negative-n (\%) & $27(24)$ \\
\hline Appendicular & \\
Inflammation & $86(75)$ \\
Positive-n (\%) & $28(25)$ \\
Negative- $n(\%)$ & \\
\hline
\end{tabular}

\begin{tabular}{|c|c|c|c|c|}
\hline \multirow{4}{*}{$\begin{array}{l}\text { C- } \\
\text { Reactive } \\
\text { Protein }\end{array}$} & & \multicolumn{2}{|c|}{$\begin{array}{l}\text { Appendicular } \\
\text { Inflammation }\end{array}$} & \multirow{2}{*}{$\begin{array}{l}\text { Statistical } \\
\text { Relation } \\
\text { Sensitivity=94\% } \\
\text { Specificity }=78 \%\end{array}$} \\
\hline & & $\begin{array}{l}\text { Positive } \\
(\mathrm{N}=86)\end{array}$ & $\begin{array}{l}\text { Negative } \\
(\mathrm{N}=28)\end{array}$ & \\
\hline & Positive & 81 & 6 & $P P V=93 \%$ \\
\hline & Negative & 5 & 22 & $N P V=74 \%$ \\
\hline
\end{tabular}

\begin{tabular}{|c|c|}
\hline Alternative diagnosis & Value; n (\%) \\
\hline Ruptured Ovarian Cysts & 4(14) \\
\hline Pelvic Inflammatory Disease & $3(11)$ \\
\hline Mesenteric Lymphadenitis & $3(11)$ \\
\hline Ovarian cyst Torsion & $1(3)$ \\
\hline Non-Specific Abdominal Pain & $17(61)$ \\
\hline
\end{tabular}

\section{Discussion}

Commonest surgical emergency, having no set criteria yet, to reach the correct diagnosis each time, is the main dilemma in acute appendicitis. Reaching the correct diagnosis in this case is an art, but the skill varies. Subjective criteria and scoring systems make it tough to reach the correct diagnosis all the time. Consequently, the rate of negative explorations for acute appendicitis continues to remain high. ${ }^{9,10}$ Making diagnosis of acute appendicitis among the elderly and females is rather more challenging, as in elderly, usual textbook signs are often diminished or absent, similarly in females, signs and symptoms are vague most of the time due to the wide range of causes, therefore the chances of wrong diagnosis are highest. ${ }^{6}$ The negative appendectomy rate of $24.56 \%$ in our study is inacceptable range; however it is relatively on higher end of $15 \%$ to $25 \%$ range mentioned in different studies ${ }^{6,9-11}$. So, it means that, there is a need to use more diagnostic tests, particularly in those patients in which the clinical diagnosis is dubious. Using more widely available and interpretable tests for this purpose is a key issue.

Good history taking and sound clinical examination organized in different scoring systems helps us to reach the diagnosis in most of 
the cases. ${ }^{4}$ It is most cost effective, repeatable, fast and widely used method specially in periphery but the clinical presentation shows a wide range of variations, many other acute abdominal conditions also mimic acute appendicitis and missing a case of acute appendicitis can result in gangrenous perforation, abscess formation, peritonitis and sepsis. This subjective approach must be augmented with chemical markers or radiological assistance wherever they are available. Although ultrasound and CT scan have improved the diagnosis, but they are still not available widely in periphery. CRP, an acute phase protein, was first recognized in 1930 by Tillet and Francis, is produced by hepatocytes in response to tissue injury. ${ }^{12}$ CRP is relatively a cheap and widely available test compared to more expensive and operator dependent radiological techniques specially in periphery. So, CRP is long being used in diagnosis of different clinical conditions. Varying results are present in different studies showing its relation to acute appendicitis to be uncertain but meta-analysis and systematic reviews concluded that CRP not alone but in combination with other markers like raised WBCs, procalcitonin, hyperbilirubinemia, shows strong relationship with diagnosing acute appendicitis. ${ }^{4,6,13}$

There are many studies of different serological markers related to diagnosis of acute appendicitis, some are termed as more efficient but we have to keep in mind ground realities of our healthcare system, where availability and cost are main concerns and this is what we addressed in our study framework. Serum CRP is widely available, in patients with suspected appendicitis, it is a very sensitive investigation. ${ }^{2}$ In our study, sensitivity of C-reactive protein is consistent with previous studies $^{1-3,16}$. However serum CRP has a relatively low specificity as CRP is also increased in many other infective and non-infective conditions.

Our study acknowledges CRP a very supportive diagnostic modality in acute appendicitis, but it still does not substitute the clinical diagnostic skills of general surgeons, it only supports the surgeons in diagnosis as mentioned in previous studies. ${ }^{14,15}$ If in a patient presenting with pain right iliac fossa, both CRP and white cell counts are normal, then acute appendicitis is rendered very improbable. ${ }^{4} \mathrm{~A}$ normal preoperative serum CRP in patients with pain right iliac fossa is most likely associated with a normal appendix so deferring surgery can reduce the rate of negative explorations, thus reducing unwanted morbidity associated with operative therapy. ${ }^{7-9,16}$ Studies also reveal that CRP is not related to diagnosis of acute appendicitis, but it can suggest, degree of inflammation of appendix and need of early intervention. ${ }^{18}$ CRP as a supplementary test can reduce the rate of negative appendectomies and their sequel specially where the new and improved diagnostic facilities are not available.

\section{Conclusion}

CRP analysis augments the clinical diagnosis of acute appendicitis. It is highly sensitive but has a relatively low specificity.

It was a single centred study, sample size was small, sampling technique used was nonprobability consecutive and qualitative CRP detection technique was used.

\section{Acknowledgements:}

We would like to acknowledge the supervision and guidance of our mentor Dr. Innayat Ullah Baig

\section{References}

1. Al-Abed YA, Alobaid N, Myint F. Diagnostic markers in acute appendicitis. Am J Surg. 2015;209(6):1043 7. Doi:10.1016/j.amjsurg.2014.05.024

2. Abedi S, Ebrahimi M, Zolfaghari P, Nourian J, Yarmohammadi M, Yahyaei E, et al. Comparison of Diagnostic Value of ESR, CRP and Leukocytosis with Pathologic Findings among Patients with Acute Appendicitis. Int J Health Studies. 2018;3(4). Doi:10.22100/ijhs.v3i4.287.

3. Xharra S, Gashi-Luci L, Xharra K, Veselaj F, Bicaj B, Sada $F$, et al. Correlation of serum C-reactive protein, white blood count and neutrophil percentage with histopathology findings in acute appendicitis. World J Emerg Surg. 2012;7(1):1-6. Doi:10.1186/1749-7922-7-27

4. Yu CW, Juan LI, Wu MH, Shen CJ, Wu JY, Lee CC. Systematic review and meta-analysis of the diagnostic accuracy of procalcitonin, C-reactive protein and white blood cell count for suspected acute appendicitis. Br J Surg. 2013;100(3):322-9. Doi:10.1002/bjs.900 
5. Craig S, Dalton S. Diagnosing appendicitis: What works, what does not and where to go from here? J Paediatr Child Health. 2016;52(2):168-73. Doi:10.1111/jpc.12998

6. Shogilev DJ, Duus N, Odom SR, Shapiro NI. Diagnosing appendicitis: evidence-based review of the diagnostic approach in 2014. West J Emerg Med. 2014;15(7):859.

Doi:10.5811/westjem.2014.9.21568

7. Peyvasteh $M$, Askarpour $\mathrm{S}$, Javaherizadeh $\mathrm{H}$, Besharati S. Modified Alvarado score in children with diagnosis of appendicitis. Arq Bras Cir Dig (São Paulo). 2017;30(1):51-2. Doi:10.1590/01026720201700010014

8. Ramula $M$, Lakshmipathy $N$, Karthik $A$, Krishnamurthy A. A comprehensive study on diagnostic value of quantitative C-reactive protein measurement in acute appendicitis. J Evol Med Dent Sci. 2016;5(69):4995-9.

9. Ohle R, O'Reilly F, O'Brien KK, Fahey T, Dimitrov BD. The Alvarado score for predicting acute appendicitis: a systematic review. BMC Med. 2011;9(1):139. Doi:10.1186/1741-7015-9-139

10. Msolli MA, Beltaief K, Bouida W, Jerbi N, Grissa MH, Boubaker $\mathrm{H}$, et al. Value of early change of serum $\mathrm{C}$ reactive protein combined to modified Alvarado score in the diagnosis of acute appendicitis. BMC Emerg Med. 2018;18(1):15. Doi:10.1186/s12873018-0166-5

11. Jamaluddin $M$, Hussain SM, Ahmad $H$. Acute appendicitis with normal total leukocyte Count. J Surg Academia. 2013;3(1):2-6.
12. Buyukbese Sarsu S, Sarac F. Diagnostic value of white blood cell and C-reactive protein in pediatric appendicitis. Biomed Res Int.;2016. Doi:10.1155/2016/6508619

13. Salih IK, Al-Dabbagh AJ, Hassan QA. The Value of Inflammatory Markers in Acute Appendicitis: A diagnostic accuracy study. PaK J Med Health Sci. 2017;11(4):1607-11.

14. Dayawansa NH, Segan JD, Yao HH, Chong HI, Sitzler PJ. Incidence of normal white cell count and Creactive protein in adults with acute appendicitis. ANZ J Surg. 2018;88(6):539-43. Doi:10.1111/ans.13760

15. McGowan DR, Sims HM, Zia K, Uheba M, Shaikh IA. The value of biochemical markers in predicting a perforation in acute appendicitis. ANZ J Surgery. 2013;83(1-2):79-83. Doi:10.1111/ans.12032

16. Aydin S, Fatihoglu E, Ramadan H, Akhan BS, Koseoglu EN. Alvarado Score, Ultrasound, and CRP: How to Combine Them for the Most Accurate Acute Appendicitis Diagnosis. Iran J Radiol. 2017;14(2). Doi: 10.5812/iranjradiol.38160

17. Ghimire R, Sharma A, Bohara S. Role of C-reactive protein in acute appendicitis. Kathmandu Univ Med J. 2016;14(54):130-3. PMID: 28166068

18. Kaya B, Sana B, Eris C, Karabulut K, Bat O, Kutanis $R$. The diagnostic value of D-dimer, procalcitonin and CRP in acute appendicitis. Int J Med Sci. 2012;9(10):909. Doi: 10.7150/ijms.4733 